Bull. Mater. Sci., Vol. 30, No. 1, February 2007, pp. 43-49. (c) Indian Academy of Sciences.

\title{
Synthesis, characterization and ion exchange properties of zirconium(IV) tungstoiodophosphate, a new cation exchanger
}

\author{
WEQAR AHMAD SIDDIQUI* and SHAKEEL AHMAD KHAN \\ Department of Applied Sciences \& Humanities, Faculty of Engineering and Technology, Jamia Millia Islamia, \\ New Delhi 110 025, India
}

MS received 16 June 2006; revised 9 November 2006

\begin{abstract}
Zirconium(IV) tungstoiodophosphate has been synthesized under a variety of conditions. The most chemically and thermally stable sample is prepared by adding a mixture of aqueous solutions of $0.5 \mathrm{~mol} \mathrm{~L}^{-1}$ sodium tungstate, potassium iodate and $1 \mathrm{~mol} \mathrm{~L}^{-1}$ orthophosphoric acid to aqueous solution of $0 \cdot 1 \mathrm{~mol}^{-1}$ zirconium(IV) oxychloride. Its ion exchange capacity for $\mathrm{Na}^{+}$and $\mathrm{K}^{+}$was found to be $2 \cdot 20$ and $2 \cdot 35 \mathrm{meq}^{-1}$ dry exchanger, respectively. The material has been characterized on the basis of chemical composition, $\mathrm{pH}$ titration, Fourier transform infrared spectroscopy (FTIR) and thermogravimetric analysis. The effect on the exchange capacity of drying the exchanger at different temperatures has been studied. The analytical importance of the material has been established by quantitative separation of $\mathrm{Pb}^{2+}$ from other metal ions.
\end{abstract}

Keywords. Synthesis; characterization; zirconium(IV) tungstoiodophosphate.

\section{Introduction}

Ion exchangers have played a prominent role in water processing and in the chemical industry. Meeting the stringent coolant purity requirements of the nuclear industry is solely attributable to ion exchangers. In the last decade, ion exchangers have been used extensively in the chemical decontamination process for metal ion recovery, regeneration of decontaminants and removal of the formulation chemicals from the coolant (Velmurugan et al 1991). Therefore, there is a continuing need to find new inorganic ion exchangers, which are capable of removing toxic substances from aqueous effluents (Hafez et al 2001), as they have good stability toward temperature, ionizing radiation, and oxidizing solutions.

Synthetic inorganic ion exchangers based on tetravalent metals have been objects of considerable study in recent years because of their selectivity and intercalation properties (Qureshi et al 1996; Zhaong et al 1996; Jaimez et al 1997; Sirlei and Claudio 1997; Ferragina et al 2001; Clearfield and Wang 2002; Hayshi et al 2002). Zirconium-based ion exchangers have received attention because of their excellent ion-exchange behaviour and some important chemical applications in the field of ion exchange, ion-exchange membrane, and solid-state electrochemistry. Heteropolyacid salts based on tin(IV), titanium(IV), zirconium(IV), and thorium(IV) have been reported in the literature as ion-exchange materials. These materials have been found to have better properties than the simple salts

\footnotetext{
*Author for correspondence (siddiqui_chem@yahoo.co.in)
}

of metals. The selectivity may be enhanced by varying the composition of materials.

The present work is concerned with zirconium(IV)-based four-component ion exchangers. The literature reveals that several three-component ion exchangers, i.e. zirconium (IV) iodooxalate (Singh et al 2002), zirconium(IV) iodovanadate (Singh et al 2003), zirconium(IV) phosphosilicate (Choube and Turel 2003), zirconium(IV) selenomolybdate (Gupta et al 2000), zirconium(IV) aluminophosphate (Varshney et al 1998), zirconium(IV) arsenovanadate (Qureshi et al 1995), zirconium(IV) phosphoborate (Mittal and Singh 1995), zirconium(IV) tungstophosphate (Gupta and Varshney 1997), zirconium(IV) tungstatephenolate (Tandon et al 1996), zirconium(IV) iodophosphate (Nabi et al 1996), zirconium(IV) selenophosphate (Qureshi and Rehman 1987a) and zirconium(IV) iodomolybdate (Qureshi and Rehman 1987b) have been studied for their synthesis, ion-exchange behaviour and analytical applications. However, the newly synthesized ion-exchanger, zirconium(IV) tungstoiodophosphate has increased ion exchange capacity and higher stability at elevated temperature.

This paper deals with the synthesis, characterization and ion exchange properties of zirconium (IV) tungstoiodophosphate as a new inorganic ion exchanger.

\section{Experimental}

\subsection{Reagent and chemicals}

Zirconium(IV) oxychloride $\left(\mathrm{ZrOCl}_{2} \cdot 8 \mathrm{H}_{2} \mathrm{O}\right)$, sodium tungstate $\left(\mathrm{Na}_{2} \mathrm{WO}_{4} \cdot 2 \mathrm{H}_{2} \mathrm{O}\right)$ and potassium iodate $\left(\mathrm{KIO}_{3}\right)$ were 
Table 1. Conditions of synthesis and few properties of different samples of zirconium(IV) tungstoiodophosphate.

\begin{tabular}{|c|c|c|c|c|c|c|c|c|}
\hline \multirow[b]{2}{*}{ Sample no. } & \multicolumn{4}{|c|}{ Molar conc. (M) } & \multirow[b]{2}{*}{ Mixing } & \multirow[b]{2}{*}{$\mathrm{pH}$} & \multirow{2}{*}{$\begin{array}{l}\text { Appearance of beads } \\
\text { after drying at } 40^{\circ} \mathrm{C}\end{array}$} & \multirow[b]{2}{*}{ I.E.C. (meq/g) } \\
\hline & $\mathrm{Zr}$ & $\mathrm{WO}_{4}^{2-}$ & $\mathrm{IO}_{3}^{-}$ & $\mathrm{PO}_{4}^{3-}$ & & & & \\
\hline ZTIP1 & $0 \cdot 1$ & $0 \cdot 5$ & $0 \cdot 5$ & 1 & $1: 1: 1: 1$ & 1 & White gelatinous & $1 \cdot 20$ \\
\hline ZTIP2 & $0 \cdot 1$ & $0 \cdot 5$ & $0 \cdot 5$ & 1 & $1: 2: 1: 1$ & 1 & White gelatinous & $0 \cdot 78$ \\
\hline ZTIP3* & $0 \cdot 1$ & $0 \cdot 5$ & $0 \cdot 5$ & 1 & $1: 1: 3: 1$ & 1 & White gelatinous & $2 \cdot 20$ \\
\hline ZTIP4 & $0 \cdot 1$ & $0 \cdot 5$ & 0.5 & 1 & $2: 1: 1: 1$ & 1 & White gelatinous & $1 \cdot 40$ \\
\hline ZTIP5 & $0 \cdot 1$ & $0 \cdot 5$ & 0.5 & 1 & $1: 1: 2: 1$ & 1 & White gelatinous & 1.00 \\
\hline
\end{tabular}

obtained from $\mathrm{CDH}$ (India), while orthophosphoric acid $\left(\mathrm{H}_{3} \mathrm{PO}_{4}\right)$ was a Qualigens (India) product. All other reagents and chemicals were of analytical grade.

\subsection{Instrumentation}

Systronic digital $\mathrm{pH}$ meter, Bausch and Lomb spectronic 20, FTIR model Shimadzu 820 pc, Philips X-ray unit, Duprot 900 and 950 thermal analyser and an electric shaking machine were used for $\mathrm{pH}$ measurements, absorbance measurements, IR studies, X-ray diffraction, thermal analysis and shaking, respectively.

\subsection{Synthesis of ion exchange material}

A number of samples were prepared by adding $0 \cdot 1 \mathrm{M}$ $\mathrm{ZrOCl}_{2} \cdot 8 \mathrm{H}_{2} \mathrm{O}$ solution to a mixture of $0.5 \mathrm{M}$ sodium tungstate, potassium iodate and $1 \mathrm{M}$ orthophosphoric acid, in different volume ratios with intermittent shaking of the mixture and maintaining the $\mathrm{pH}$ at 1 , as given in table 1 .

The resultant gel was allowed to stand by keeping it for $24 \mathrm{~h}$ at room temperature and then filtered. The excess acid was removed by washing with demineralized water and the material was dried in an electric oven at $50 \pm 5^{\circ} \mathrm{C}$. The dried gel was put into the demineralized water to obtain granules of uniform size suitable for column operation. The dried granules were converted into the $\mathrm{H}^{+}$form by keeping them immersed with $\mathrm{HNO}_{3}\left(1 \mathrm{~mol} \mathrm{~L}^{-1}\right)$ for $24 \mathrm{~h}$ with occasional shaking and intermittently replacing the supernatant liquid with fresh acid. The material thus obtained was then washed with demineralized water to remove the excess acid before drying finally at $50 \pm 5^{\circ} \mathrm{C}$ and sieved to obtain particles of size 50-70 mesh.

\subsection{Ion-exchange capacity (IEC)}

The ion exchange capacity of the material was determined by the column process (table 2). One $\mathrm{g}$ of the exchanger $\left(\mathrm{H}^{+}\right.$form) was packed in a glass column and washed with DMW to remove any excess of acid that remained on the particles. $250 \mathrm{ml}$ of $1 \mathrm{M}$ solution of different salts was passed through the column maintaining the flow rate at $1 \mathrm{ml} \mathrm{min}{ }^{-1}$. The effluent was collected and titrated against a standard $\mathrm{NaOH}$ solution to determine the total $\mathrm{H}^{+}$ions released.
Table 2. Ion exchange capacity (meq $\mathrm{g}^{-1}$ dry exchangers) of zirconium(IV) tungstoiodophosphate (ZTIP3).

\begin{tabular}{lllcc}
\hline $\begin{array}{l}\text { Sl. } \\
\text { no. }\end{array}$ & Cation & Salt used & $\begin{array}{c}\text { I.E.C } \\
\left(\mathrm{meq} \mathrm{g}^{-1}\right)\end{array}$ & $\begin{array}{c}\mathrm{pH} \\
\text { titration }\end{array}$ \\
\hline 1. & $\mathrm{Li}^{+}$ & $\mathrm{LiCl}$ & 1.90 & \\
2. & $\mathrm{Na}^{+}$ & $\mathrm{NaCl}$ & $2 \cdot 20$ & $2 \cdot 28$ \\
3. & $\mathrm{~K}^{+}$ & $\mathrm{KCl}$ & $2 \cdot 35$ & $2 \cdot 45$ \\
4. & $\mathrm{Mg}^{2+}$ & $\mathrm{Mg}\left(\mathrm{NO}_{3}\right)_{2}$ & 1.45 & \\
5. & $\mathrm{Sr}^{2+}$ & $\mathrm{Sr}\left(\mathrm{NO}_{3}\right)_{2}$ & 1.68 & \\
6. & $\mathrm{Ca}^{2+}$ & $\mathrm{Ca}\left(\mathrm{NO}_{3}\right)_{2}$ & 1.85 & \\
\hline
\end{tabular}

\subsection{Chemical composition}

For the determination of chemical composition of the sample, ZTIP3, $0 \cdot 1 \mathrm{~g}$ of exchanger was dissolved in minimum amount of hot concentrated $\mathrm{H}_{2} \mathrm{SO}_{4}$. The solution was diluted to $100 \mathrm{ml}$ with DMW. The amounts of zirconium and iodate were determined spectrophotometrically using Alizarin Red-S and pyrogallol as colouring reagents, respectively. Tungsten was determined gravimetrically and phosphate was determined titrametrically using the standard method (Reilley et al 1959).

\subsection{Thermal stability}

Thermogravimetric analysis of the material in the $\mathrm{H}^{+}$ form was performed at a heating rate of $10^{\circ} \mathrm{C} \mathrm{min}^{-1}$. The effect of heating on the ion-exchange capacity of the material was also examined. The material in $\mathrm{H}^{+}$form was heated at different temperatures for $1 \mathrm{~h}$ in a muffle furnace and the ion-exchange capacity for $\mathrm{Na}^{+}$was evaluated by the column process after cooling it at room temperature. The results are summarized in table $3 \mathrm{a}$.

\section{7 pH titration}

$\mathrm{pH}$ titration was performed by the batch process using the method of Topp and Pepper (1949). $500 \mathrm{mg}$ portions of the exchanger in the $\mathrm{H}^{+}$form were placed in each of the several $250 \mathrm{ml}$ conical flasks followed by equimolar solution of alkali metal chlorides and their hydroxides in different volume ratios, the final volume being $50 \mathrm{ml}$ to maintain the ionic strength constant. The $\mathrm{pH}$ of each solution was 
Table 3a. Thermal stability of zirconium(IV) tungstoiodophosphate (ZTIP3) after heating to various temperatures for $1 \mathrm{~h}$.

\begin{tabular}{lccc}
\hline Drying temp $\left({ }^{\circ} \mathrm{C}\right)$ & $\begin{array}{c}\mathrm{Na}^{+} \text {ion exchange capacity } \\
(\text { meq dry/g) }\end{array}$ & Change in colour & $\%$ Retention \\
\hline 40 & $2 \cdot 20$ & White & $100 \cdot 00$ \\
100 & 1.82 & White & 82.73 \\
200 & 1.60 & White & 72.73 \\
300 & 1.35 & White & 61.37 \\
400 & 1.00 & White & $45 \cdot 46$ \\
500 & 0.90 & Gray & 40.91 \\
600 & $0 \cdot 78$ & Dark gray & 35.46 \\
\hline
\end{tabular}

Table 3b. Effect of drying temperature on ion exchange capacity for various inorganic ion exchangers.

\begin{tabular}{lccccccc}
\hline & \multicolumn{7}{c}{$\begin{array}{c}\text { Ion exchange capacity (meq g } \\
\text { at different temperatures }\end{array}$} \\
\cline { 2 - 8 } Inorganic ion exchanger & $40^{\circ} \mathrm{C}$ & $100^{\circ} \mathrm{C}$ & $200^{\circ} \mathrm{C}$ & $300^{\circ} \mathrm{C}$ & $400^{\circ} \mathrm{C}$ & $500^{\circ} \mathrm{C}$ & $600^{\circ} \mathrm{C}$ \\
\hline Zirconium(IV) tungstoiodophosphate & $2 \cdot 20$ & 1.82 & 1.60 & 1.35 & 1.00 & 0.90 & 0.78 \\
Tin(IV) tungstovanadophosphate & 1.83 & 1.80 & 1.50 & 1.25 & 0.97 & $0 \cdot 85$ & - \\
Zirconium(IV) iodophosphate & 1.75 & 1.60 & 1.40 & 1.00 & 0.92 & 0.82 & 0.66 \\
Zirconium(IV) iodomolybdate & 1.54 & 1.30 & 1.00 & 0.78 & 0.66 & 0.42 & $0 \cdot 16$ \\
\hline
\end{tabular}

measured and plotted against milliequivalents of $\mathrm{OH}$ ions. The capacity corresponding to inflection point was also calculated from the curve.

\subsection{Chemical stability}

$500 \mathrm{mg}$ of the sample, ZTIP3, was shaken with $50 \mathrm{ml}$ of the various solutions at $30 \pm 2{ }^{\circ} \mathrm{C}$ for $6 \mathrm{~h}$. The amounts of zirconium, iodate and phosphate released in the solutions were determined spectrophotometrically with alizarin red-s, pyrogallol and molybdophosphoric acid, and tungsten was determined gravimetrically (Reilley et al 1959; Davis 1963).

The material is found to be quite stable in lower concentration of mineral acid, such as $\mathrm{HCl}, \mathrm{H}_{2} \mathrm{SO}_{4}$, and $\mathrm{HNO}_{3}$. However, the sample is quite stable in organic acid like acetic acid. The results are summarized in table 4 .

\subsection{Distribution studies}

$200 \mathrm{mg}$ portion of the dry exchanger in $\mathrm{H}^{+}$form were equilibrated with $20 \mathrm{ml}$ of different metal ion solutions in the required medium and kept for $24 \mathrm{~h}$ with intermittent shaking. The initial metal ion concentration $(0 \cdot 01 \mathrm{M})$ in the solution was so adjusted that it did not exceed $3 \%$ of total ion exchange capacity of the material. The determination before and after equilibrium were carried out volumetrically using EDTA as the titrant (Reilley et al 1959).

The $K d$ values, as summarized in table 5, were obtained by the formula

$$
K d=(I-F) / F^{*} V / M(\mathrm{ml} / \mathrm{g}),
$$

where $I$ is the initial metal ion concentration, $F$ the final metal ion concentration, $V$ the volume of solution and $M$ the mass of the exchanger.

\subsection{FTIR spectrum}

FTIR spectrum of sample ZTIP3 was obtained by $\mathrm{KBr}$ disc method.

\subsection{Separation of metal ions achieved}

Several binary separations were tried using a column of internal diameter, $\sim 0.6 \mathrm{~cm}$, containing $2 \mathrm{~g}$ of the material. The column was washed thoroughly with demineralized water and the mixture to be separated was loaded on to it, maintaining a flow rate of $\sim 2-3$ drops $\min ^{-1}\left(0 \cdot 15 \mathrm{ml} \mathrm{min}^{-1}\right)$. The separation was achieved by passing a suitable solvent through the column as eluent and the metal ions in the effluent were determined quantitatively by EDTA titrations. Table 6 gives the salient features of the separations.

\section{Results and discussion}

The results from the study of the ion-exchange capacity of various samples of zirconium (IV) tungstoiodophosphate are presented in table 1 . The improvement in the ionexchange capacity and chemical stability seem to be much higher for sample ZTIP3 and, therefore, this sample 
Table 4. Chemical stability of zirconium(IV) tungstoiodophosphate (ZTIP3) in different solvents.

\begin{tabular}{|c|c|c|c|c|}
\hline Solution & $\begin{array}{l}\mathrm{Zr}(\mathrm{IV}) \text { released } \\
\quad(\mathrm{mg} / 50 \mathrm{ml})\end{array}$ & $\begin{array}{c}\mathrm{WO}_{4}^{2-} \text { released } \\
(\mathrm{mg} / 50 \mathrm{ml})\end{array}$ & $\begin{array}{c}\mathrm{IO}_{3}^{-} \text {released } \\
(\mathrm{mg} / 50 \mathrm{ml})\end{array}$ & $\begin{array}{c}\mathrm{PO}_{4}^{3-} \text { released } \\
(\mathrm{mg} / 50 \mathrm{ml})\end{array}$ \\
\hline $\mathrm{H}_{2} \mathrm{O}$ & $0 \cdot 00$ & $0 \cdot 00$ & $0 \cdot 00$ & $0 \cdot 00$ \\
\hline $0 \cdot 1 \mathrm{M} \mathrm{HClO}_{4}$ & $0 \cdot 00$ & $0 \cdot 28$ & $0 \cdot 38$ & $0 \cdot 039$ \\
\hline $1 \cdot 0 \mathrm{M} \mathrm{HClO}_{4}$ & $0 \cdot 46$ & $0 \cdot 98$ & $1 \cdot 38$ & $1 \cdot 10$ \\
\hline $0 \cdot 1 \mathrm{M} \mathrm{HNO}_{3}$ & $0 \cdot 00$ & $0 \cdot 18$ & $0 \cdot 22$ & $0 \cdot 31$ \\
\hline $0.5 \mathrm{M} \mathrm{HNO}_{3}$ & $0 \cdot 00$ & $0 \cdot 38$ & $0 \cdot 28$ & 0.90 \\
\hline $1.0 \mathrm{M} \mathrm{HNO}_{3}$ & $0 \cdot 30$ & $0 \cdot 78$ & 0.98 & $0 \cdot 18$ \\
\hline $0 \cdot 1 \mathrm{M} \mathrm{H}_{2} \mathrm{SO}_{4}$ & 0.00 & $0 \cdot 34$ & $0 \cdot 34$ & $0 \cdot 34$ \\
\hline $0 \cdot 5 \mathrm{M} \mathrm{H}_{2} \mathrm{SO}_{4}$ & $0 \cdot 91$ & 0.78 & 0.94 & 1.00 \\
\hline $1 \cdot 0 \mathrm{M} \mathrm{H}_{2} \mathrm{SO}_{4}$ & 1.41 & $0 \cdot 94$ & 1.78 & $0 \cdot 19$ \\
\hline $0 \cdot 1 \mathrm{M} \mathrm{HCl}$ & 0.00 & $0 \cdot 00$ & $0 \cdot 18$ & 0.78 \\
\hline $0.5 \mathrm{M} \mathrm{HCl}$ & 0.68 & $0 \cdot 42$ & $0 \cdot 68$ & $1 \cdot 30$ \\
\hline $1.0 \mathrm{M} \mathrm{HCl}$ & $1 \cdot 55$ & $0 \cdot 78$ & $1 \cdot 20$ & $0 \cdot 31$ \\
\hline $1 \mathrm{M} \mathrm{CH}_{3} \mathrm{COOH}$ & $0 \cdot 00$ & $0 \cdot 21$ & $0 \cdot 28$ & $0 \cdot 39$ \\
\hline $0 \cdot 1 \mathrm{M} \mathrm{NaOH}$ & $0 \cdot 98$ & $3 \cdot 10$ & $3 \cdot 19$ & $3 \cdot 28$ \\
\hline $2 \cdot 0 \mathrm{M} \mathrm{NaOH}$ & \multicolumn{3}{|c|}{ Completely dissolved } & \\
\hline
\end{tabular}

Table 5. $K d$ values of metal ions on zirconium(IV) tungstoiodophosphate (ZTIP3) in different solvents.

\begin{tabular}{|c|c|c|c|c|c|c|c|c|c|c|}
\hline $\begin{array}{l}\text { Metal } \\
\text { ions }\end{array}$ & DMW & $\begin{array}{c}0.01 \mathrm{M} \\
\mathrm{HNO}_{3}\end{array}$ & $\begin{array}{l}0 \cdot 1 \mathrm{M} \\
\mathrm{HNO}_{3}\end{array}$ & $\begin{array}{c}1 \mathrm{M} \\
\mathrm{HNO}_{3}\end{array}$ & $\begin{array}{c}0 \cdot 01 \mathrm{M} \\
\mathrm{HCl}\end{array}$ & $\begin{array}{c}0 \cdot 1 \mathrm{M} \\
\mathrm{HCl}\end{array}$ & $\begin{array}{l}1 \mathrm{M} \\
\mathrm{HCl}\end{array}$ & $\begin{array}{l}0.01 \mathrm{M} \\
\mathrm{HClO}_{4}\end{array}$ & $\begin{array}{c}0 \cdot 1 \mathrm{M} \\
\mathrm{HClO}_{4}\end{array}$ & $\begin{array}{c}1 \mathrm{M} \\
\mathrm{HClO}_{4}\end{array}$ \\
\hline $\mathrm{Al}^{3+}$ & 9100 & 4500 & 2950 & 2150 & 3100 & 2050 & 1620 & 4500 & 3041 & 2150 \\
\hline $\mathrm{Ba}^{2+}$ & 2916 & 1002 & 832 & 650 & 1540 & 1150 & 720 & 1000 & 740 & 610 \\
\hline $\mathrm{Ca}^{2+}$ & 1700 & 1100 & 602 & 540 & 1050 & 640 & 520 & 1175 & 710 & 510 \\
\hline $\mathrm{Cu}^{2+}$ & 7900 & 3600 & 1440 & 910 & 2153 & 975 & 821 & 2633 & 1171 & 711 \\
\hline $\mathrm{Co}^{2+}$ & 3600 & 1400 & 940 & 800 & 1220 & 880 & 840 & 1402 & 1260 & 940 \\
\hline $\mathrm{Cd}^{2+}$ & 4500 & 1224 & 904 & 740 & 1350 & 1071 & 1000 & 1460 & 741 & 510 \\
\hline $\mathrm{Fe}^{3+}$ & 5400 & 2700 & 2700 & 2700 & 5100 & 2600 & 2600 & 2700 & 1450 & 830 \\
\hline $\mathrm{Hg}^{2+}$ & 4100 & 1900 & 1504 & 1066 & 2133 & 1850 & 1500 & 1850 & 1530 & 1230 \\
\hline $\mathrm{K}^{+}$ & 1000 & 445 & 320 & 240 & 521 & 380 & 280 & 410 & 340 & 340 \\
\hline $\mathrm{Mn}^{2+}$ & 2455 & 840 & 740 & 610 & 785 & 848 & 730 & 750 & 730 & 580 \\
\hline $\mathrm{Mg}^{2+}$ & 1600 & 1132 & 900 & 700 & 1600 & 840 & 741 & 1040 & 821 & 640 \\
\hline $\mathrm{Ni}^{2+}$ & 2400 & 1142 & 918 & 740 & 1100 & 821 & 710 & 1300 & 845 & 631 \\
\hline $\mathrm{Pb}^{2+}$ & 8500 & 8600 & 7100 & 1250 & 7700 & 200 & 1150 & 8600 & 2840 & 990 \\
\hline $\mathrm{Sr}^{2+}$ & 2100 & 950 & 612 & 510 & 1233 & 800 & 636 & 940 & 721 & 667 \\
\hline $\mathrm{Zn}^{2+}$ & 4100 & 1050 & 79 & 550 & 1133 & 820 & 640 & 1070 & 640 & 422 \\
\hline
\end{tabular}

was selected for detailed studies. The ion-exchange capacities for mono- and bivalent metal ions are shown in table 2 .

It is clear from the table that the capacity increases with decreasing hydrated ionic radii for both mono and bivalent metal ions. The capacities for $\mathrm{Na}^{+}$and $\mathrm{K}^{+}$obtained from $\mathrm{pH}$ titration are also presented in table 2 and it was found that the values obtained by $\mathrm{pH}$ titration are slightly higher than those obtained by column operation. Further, the $\mathrm{pH}$ titration curve showed one inflection point confirming the monofunctional behaviour of the exchanger.

The ion exchange capacity of zirconium(IV) tungstoiodophosphate is also affected by drying temperature. As the drying temperature of the material increases ion-exchange capacity decreases. The results are given in table $3 \mathrm{a}$.

A comparative study of the ion exchange capacity of different zirconium and tin based ion exchangers dried at $600^{\circ} \mathrm{C}$ gave the sequences: zirconium(IV) tungstoiodophosphate $>$ tin(IV) tungstovanadophosphate (Nabi and Siddiqui 1986) > zirconium(IV) iodophosphate (Nabi et al 1996) > zirconium(IV) iodomolybdate (Qureshi and Rehman 1987b). Moreover, zirconium(IV) tungstoiodophosphate also seems to be most thermally stable, because it retains considerable ion exchange capacity even at $600^{\circ} \mathrm{C}$.

Results showing the extent of dissolution of the material in different solutions are given in table 4. It is apparent from the table that the exchanger is quite stable in water and fairly stable in mineral acids and organic acids of moderate concentration whereas it is less stable in bases.

The titration curves with added salts are shown in figure 1. The curve in the presence of sodium salt was slightly different from that in the presence of potassium salt.

The ion exchange capacities (at $\mathrm{pH} 7$ ) calculated from these curves is 2.28 and $2.45 \mathrm{meq} \mathrm{g}^{-1}$ exchanger, which is close to the values obtained from column technique. 
Table 6. Separation of metal ions achieved on zirconium(IV) tungstoiodophosphate (ZTIP3) columns.

\begin{tabular}{lccccc}
\hline $\begin{array}{l}\text { Separation } \\
\text { achieved }\end{array}$ & $\begin{array}{c}\text { Amount loaded } \\
(\mu \mathrm{g})\end{array}$ & $\begin{array}{c}\text { Amount found } \\
(\mu \mathrm{g})\end{array}$ & $\%$ Error & Eluent used & $\begin{array}{c}\text { Volume of eluent } \\
(\mathrm{ml})\end{array}$ \\
\hline $\mathrm{Pb}(\mathrm{II})$ & 1078 & 1038 & $-3 \cdot 7$ & $1 \mathrm{M} \mathrm{HNO}_{3}$ & 40 \\
$\mathrm{Mg}(\mathrm{II})$ & 286 & 292 & $+2 \cdot 1$ & $0 \cdot 1 \mathrm{M} \mathrm{HClO}_{4}$ & 50 \\
$\mathrm{~Pb}(\mathrm{II})$ & 1091 & 1091 & $0 \cdot 00$ & $1 \mathrm{M} \mathrm{HNO}_{3}$ & 30 \\
$\mathrm{Cd}(\mathrm{II})$ & $586 \cdot 3$ & $612 \cdot 0$ & $+4 \cdot 3$ & $0 \cdot 1 \mathrm{M} \mathrm{HCl}$ & 40 \\
$\mathrm{~Pb}(\mathrm{II})$ & $856 \cdot 4$ & $812 \cdot 2$ & $-5 \cdot 2$ & $1 \mathrm{M} \mathrm{HNO}_{3}$ & 40 \\
$\mathrm{Cu}(\mathrm{II})$ & $515 \cdot 0$ & $515 \cdot 0$ & $0 \cdot 00$ & $0 \cdot 1 \mathrm{M} \mathrm{HClO}_{4}$ & 50 \\
$\mathrm{~Pb}(\mathrm{II})$ & 1020 & 1020 & $0 \cdot 00$ & $0 \cdot 1 \mathrm{M} \mathrm{HNO}_{3}$ & 40 \\
$\mathrm{Ni}(\mathrm{II})$ & 688 & $704 \cdot 2$ & $+2 \cdot 2$ & $0 \cdot 1 \mathrm{M} \mathrm{HClO}_{4}$ & 50 \\
\hline
\end{tabular}

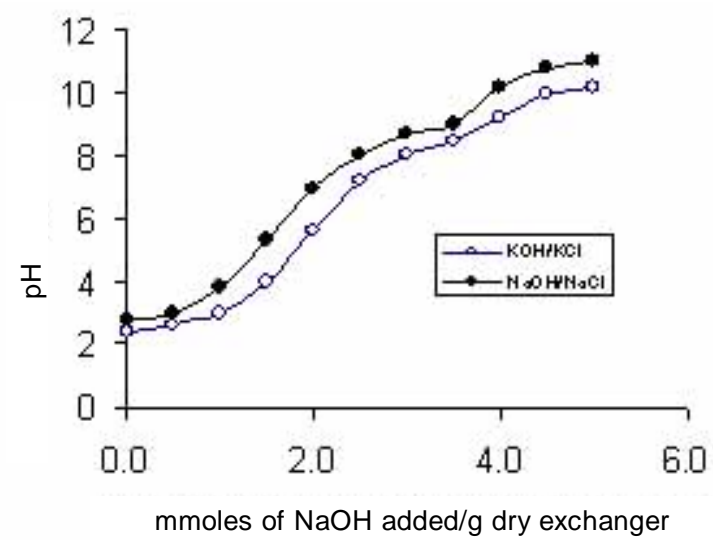

Figure 1. $\mathrm{pH}$ titration curve for zirconium(IV) tungstoiodophosphate.

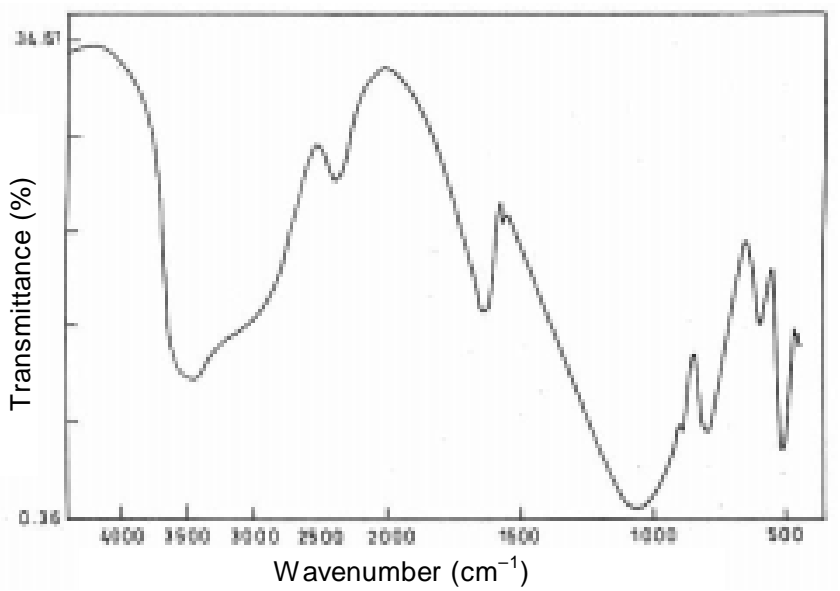

Figure 2. FTIR spectrum of zirconium(IV) tungstoiodophosphate.

The molar ratio of $\mathrm{Zr}, \mathrm{W}, \mathrm{I}$ and $\mathrm{P}$ in the ion exchanger material was estimated to be $2: 1.01: 1.08: 2 \cdot 01$, by performing chemical composition studies which can suggest the following formula of the material

$$
\left[(\mathrm{ZrO})_{2}\left(\mathrm{WO}_{3}\right)\left(\mathrm{IO}_{3}\right)\left(\mathrm{H}_{3} \mathrm{PO}_{4}\right)_{2}\right] \cdot n \mathrm{H}_{2} \mathrm{O} \text {. }
$$

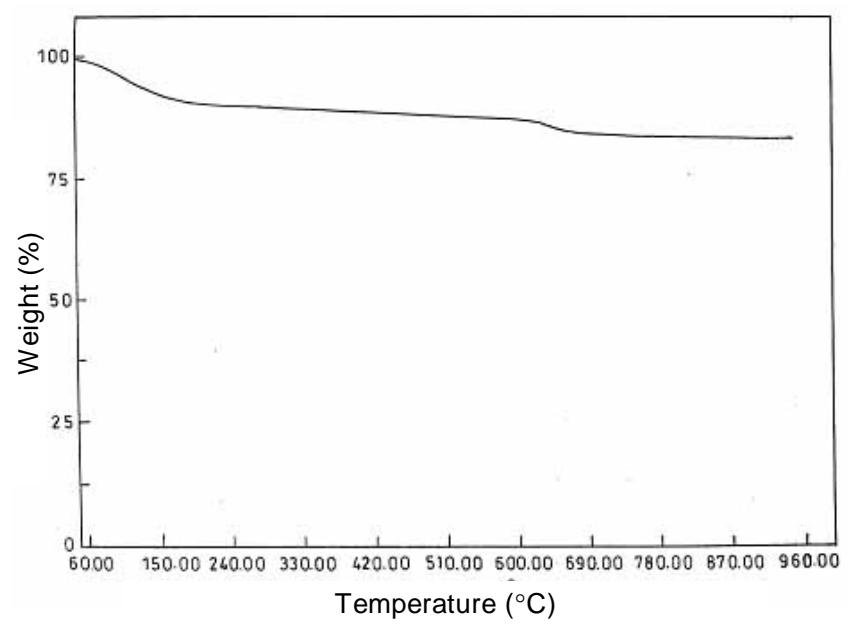

Figure 3. Thermogram of zirconium(IV) tungstoiodophosphate.

Thermogram of zirconium (IV) tungstoiodophosphate (ZTPI3) is shown in figure 3. Assuming that only the external water molecules are lost at $260^{\circ} \mathrm{C}$, the $\sim 9.73 \%$ weight loss of the mass represented by TGA curve must be due to the loss of $n \mathrm{H}_{2} \mathrm{O}$. Thus from the above structure the value of ' $n$ ' of the external water molecules can be calculated using Alberti equation (Alberti et al 1966)

$$
18 n=x(M+18 n) / 100,
$$

where $x$ is the percent weight loss $(\sim 9.73 \%)$ of the exchanger when heated up to $260^{\circ} \mathrm{C}$ and $(M+18 n)$ is the molecular weight of the material. The calculation gives $\sim 5$ for the external water molecule $(n)$ per molecule of the cation exchanger.

In FTIR (figure 2) studies the broad band in the region $3600-3000 \mathrm{~cm}^{-1}$ may be assigned to interstitial water molecule and OH group (Rao 1963). Another strong and sharp peak with a maximum of $1635 \mathrm{~cm}^{-1}$ may be due to $\mathrm{H}-\mathrm{O}-\mathrm{H}$ bonding. The spectrum also shows strong band in the region $830-500 \mathrm{~cm}^{-1}$ indicating the presence of iodate and metal oxide (Weltner and McLeod 1965; Socrates 1980).

The X-ray diffraction spectrum (figure 4) of cation exchanger zirconium(IV) tungstoiodophosphate shows a 


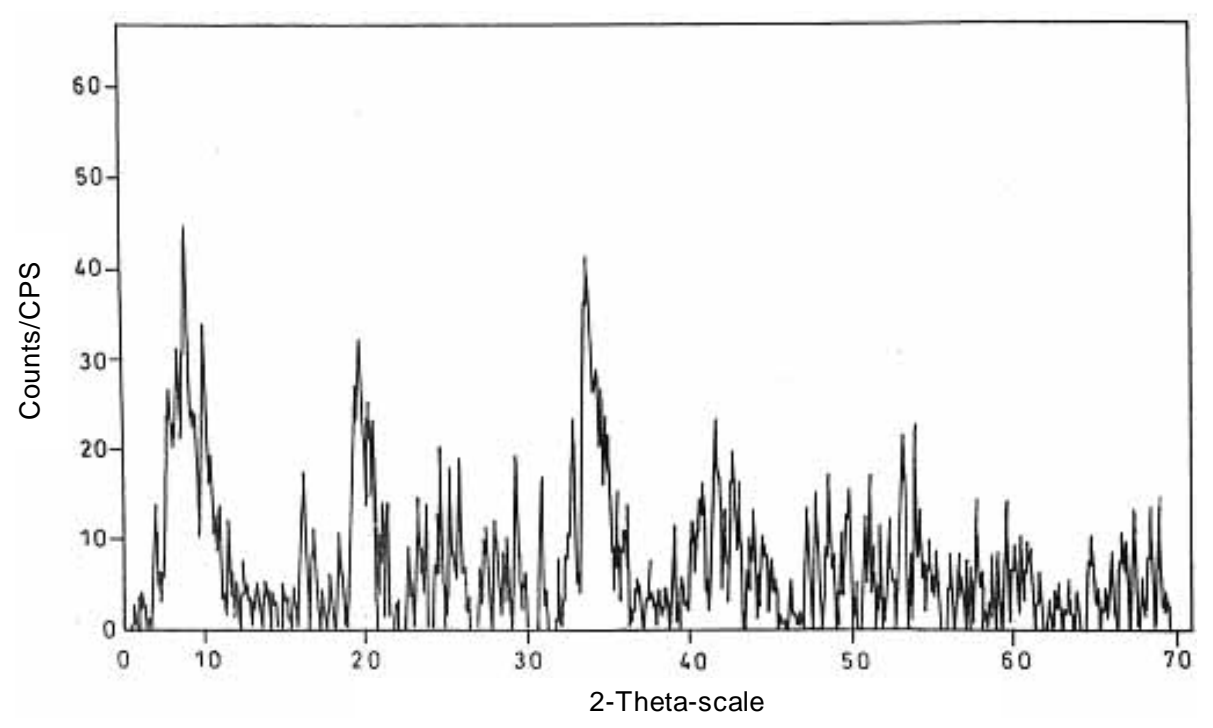

Figure 4. X-ray diffraction pattern of zirconium(IV) tungstoiodophosphate.

number of peaks at different $2 \theta$ values. The analysis of these signal peaks supports towards its crystalline nature.

In order to explore the potential of this cation exchange material in the separation of metal ions, distribution studies for 15 metal ions were performed in several solvent systems (table 5). The distribution studies showed that the material was found to possess exceptional high $K d$ values for $\mathrm{Pb}(\mathrm{II})$ and hence considered to be highly selective for $\mathrm{Pb}(\mathrm{II})$. $\mathrm{Pb}(\mathrm{II})$ has been considered as a major polluting material in water. The separation capacity of the material has been demonstrated by achieving some important binary separations such as $\mathrm{Pb}(\mathrm{II})-\mathrm{Mg}(\mathrm{II}), \mathrm{Pb}(\mathrm{II})-\mathrm{Cd}(\mathrm{II}), \mathrm{Pb}(\mathrm{II})-$ $\mathrm{Cu}(\mathrm{II}), \mathrm{Pb}(\mathrm{II})-\mathrm{Ni}(\mathrm{II})$ etc. Table 6 summarizes the salient features of these separations. The separations are quite sharp and recovery is quantitative and reproducible.

\section{Conclusions}

The results of this investigation showed that zirconium(IV) tungstoiodophosphate seems to be a promising ion-exchange material with a significant ion-exchange capacity. The ionexchange capacity (IEC) in meq $\mathrm{g}^{-1}$ for different metal ions are: $\mathrm{Li}^{+}, 1 \cdot 90 ; \mathrm{Na}^{+}, 2 \cdot 20 ; \mathrm{K}^{+}, 2 \cdot 35 ; \mathrm{Mg}^{2+}, 1 \cdot 45 ; \mathrm{Ca}^{2+}$, $1 \cdot 85 ; \mathrm{Sr}^{2+}, 1 \cdot 68$. The results from investigation of the extent of dissolution of the material in mineral acids and organic acids confirm its better chemical stability. The thermal stability of zirconium(IV) tungstoiodophosphate was compared with that of other zirconium based ion exchangers and it was concluded that it had better resistance to heat and it retains considerable ion exchange capacity even at $600^{\circ} \mathrm{C}$. The analytical importance of the material was deduced from $K d$ values for different metal ions in different solvents. The material had high affinity for $\mathrm{Pb}^{2+}$ in comparison to other metal ions studied. On the basis of this behaviour, separation of $\mathrm{Pb}^{2+}$ from various synthetic water samples has been achieved to prove the analytical applications of the material.

\section{Acknowledgements}

The authors are thankful to Prof. Masood Alam, Department of Applied Sciences \& Humanities, Faculty of Engineering and Technology, Jamia Millia Islamia, New Delhi, for his helpful suggestions and discussions. Thanks are also due to the Central Drug Research Institute, Lucknow and Textile Lab, IIT Delhi, for technical assistance.

\section{References}

Alberti G, Torraca E and Conte A 1966 J. Inorg. Nucl. Chem. 28607

Choube U N and Turel Z R 2003 Czech. J. Phys. 53539

Clearfield A and Wang Z 2002 J. Chem. Soc. Dalton Trans. 7 2937

Davis M 1963 Infrared spectroscopy and molecular structure (Amsterdam: Elsevier Publishing Co.) p. 145

Ferragina C, Cafarelli P, Di Stefanis A, Di Rocco R and Giannoccaro P 2001 Mater. Res. Bull. 361799

Gupta A P and Varshney P K 1997 React. Funct. Polym. 3267

Gupta A P, Verma G L and Ikram S 2000 React. Funct. Polym. 4331

Hafez M A, Kenway I M M, Akl M A and Lshein R R 2001 Talanta $\mathbf{5 3} 749$

Hayshi H, Onoda Y and Iwasaki T 2002 Nippon Ion Kokan Gakkaishi 1132

Jaimez E, Robert C T and Slade 1997 J. Chem. Soc. Dalton Trans. 81435

Mittal S K and Singh P P 1995 Indian J. Chem. A34 1009

Nabi S A and Siddiqui W A 1986 Bull. Chem. Soc. Jpn 592003

Nabi S A, Usmani S and Rehman N 1996 Ann. Chim. Fr. 21521 
Qureshi S Z and Rehman N 1987a Bull. Chem. Soc. Fr. 6959 Qureshi S Z and Rehman N 1987b Bull. Chem. Soc. Jpn 602627 Qureshi S Z, Khan M A and Rehman N 1995 Bull. Chem. Soc. Jpn 681611

Qureshi S Z, Jamhour R M A Q and Rehman N 1996 Ann. Chim. (Paris) 21609

Rao C N R 1963 Chemical application of infrared spectroscopy (New York: Academic Press)

Reilley C N, Schmid R W and Sadek F S 1959 J. Chem. Edu. 35555

Singh P, Rawat J P and Rehman N 2002 Indian J. Chem. A41 1616

Singh P, Rawat J P and Rehman N 2003 Talanta 59443

Sirlei R and Claudio A 1997 J. Chem. Soc. Dalton Trans. 142517
Socrates G 1980 Infrared characteristic group frequencies (New York: Wiley) p. 145

Tandon S, Pandit B and Chudasama U 1996 Trans. Met. Chem. 217

Topp N E and Pepper K W 1949 J. Chem. Soc. 3299

Varshney K G, Pandith A H and Gupta U 1998 Langmuir 14 7353

Velmurugan S, Sathyaseelam V S, Narasimhan S V and Mathur P K 1991 New development in ion exchange, in Proceedings of international conference ion exchange ICIE'91, Tokyo

Weltner W Jr and McLeod D Jr 1965 J. Phys. Chem. 693488

Zhaong M, Damodar M, Clearfield A and Peng G 1996 Chem. Matter. 81333 